\title{
EKSPLORASI AKTIVITAS SISWA MELALUI MODEL INTERAKSI LEIKIN DALAM PEMBELAJARAN MATEMATIKA
}

\author{
Sofia Sa'o ${ }^{1}$, Finsensius Yesekiel Naja ${ }^{2}$, Agustina $\mathrm{Mei}^{3}$ \\ ${ }^{1}$ Universitas Flores, Jln. Sam Ratulangi, Ende-Flores-NTT \\ ${ }^{2}$ Universitas Flores, Jln. Sam Ratulangi, Ende-Flores-NTT \\ ${ }^{3}$ Universitas Flores, Jln. Sam Ratulangi, Ende-Flores-NTT \\ Email: saosofia39@gmail.com
}

\begin{abstract}
This research focused on the difficulty of students doing interaction activities in learning mathematics in school. Sometimes even smart students will get used to silence in class. Students are not accustomed to actively interacting, even though student activities are very important in the process of learning mathematics. Activities hat occur in learning, include several aspects such as listening to the teacher's explanation, asking if there is something that has not been understood, answering the question of the teacher or other friends, having active discussions if allowed group work, solving practice questions if they are given by the teacher and so on. The activities included in it are interactive activities. Interaction in this research is an activity that occurs about the needs of the learning process, namely the relationship between teacher and student, student and teacher, student and student, and student and learning resources. The method used in this research is how the interaction that occurs is related to the interaction model. The expected results of this study are students can actively interact in every learning process in school.
\end{abstract}

Keywords: student activity; leikin interaction model

\begin{abstract}
Abstrak
Penelitian ini terfokus pada sulitnya siswa melakukan aktivitas interaksi dalam pembelajaran matematika di sekolah. Kadang siswa yang pintar sekalipun akan terbiasa diam dalam kelas. Siswa tidak terbiasa untuk aktif berinteraksi, padahal aktivitas siswa sangat penting dalam proses pembelajaran matematika. Aktivitas yang terjadi dalam pembelajaran, mencakup beberapa aspek seperti mendengarkan penjelasan guru, bertanya jika ada yang belum dipahami, menjawab pertanyaan guru atau teman lain, berdiskusi aktif jika diberikan kesempatan untuk kerja kelompok, menyelesaikan soal latihan jika diberikan oleh guru dan sebagainya. Dalam aktivitas termasuk didalamnya adalah kegiatan interaksi. Interaksi dalam penelitian ini adalah aktifitas yang terjadi dalam hubungan dengan kebutuhan pada proses pembelajaran, yaitu hubungan antara guru dengan siswa, siswa dengan guru, siswa dengan siswa dan siswa dengan sumber belajar. Metode yang digunakan dalam penelitian ini adalah bagaimana interaksi yang terjadi dikaitkan dengan model interaksi. Hasil yang diharapkan dari penelitian ini adalah siswa bisa aktif berinteraksi pada setiap proses pembelajaran di sekolah.
\end{abstract}

Kata kunci: aktivitas siswa; model interaksi leikin

\section{PENDAHULUAN}

Pendidikan pada dasarnya merupakan interaksi antara guru dengan siswa, untuk mencapai tujuan pendidikan yang berlangsung dalam lingkungan tertentu. Interaksi ini disebut interaksi pendidikan, yaitu saling berpengaruh antara guru dan siswa. Dalam saling mempengaruhi ini peranan guru lebih besar, karena kedudukannya sebagai orang yang lebih dewasa, lebih berpengalaman, lebih banyak menguasai nilai-nilai, pengetahuan dan keterampilan. Sedangkan peranan siswa lebih banyak sebagai penerima pengaruh dan pengikut (Sukmadinata, 2009). 
Menurut Titin (Holil, 2009), dalam proses interaksi dibutuhkan komponen pendukung yaitu 1) interaksi belajar memiliki tujuan yakni untuk membantu anak dalam suatu perkembangan tertentu, 2) ada suatu prosedur (jalannya interaksi) yang direncanakan, didesain untuk mencapai tujuan yang diinginkan, 3) interaksi belajar mengajar ditandai dengan satu penggarapan materi yang khusus dimana materi tersebut didesain sehingga dapat mencapai tujuan. Materi disiapkan sebelum interaksi pembelajaran dimulai, 4) ditandai dengan adanya aktivitas siswa yang merupakan syarat mutlak bagi berlangsungnya interaksi pembelajaran, 5) dalam interaksi pembelajaran guru berperan sebagai pembimbing. Guru memberikan motivasi agar terjadi proses interaksi dan sebagai mediator dalam proses pembelajaran, 6) dalam interaksi pembelajaran membutuhkan kedisiplinan, 7) ada batas waktu. Setiap tujuan diberi waktu tertentu, kapan tujuan itu harus dicapai, 8) unsur penilaian. Untuk mengetahui ketercapaian dari suatu tujuan pembelajaran diperlukan suatu kegiatan penilaian.

Berdasarkan pendapat di atas dapat disimpulkan bahwa interaksi merupakan hubungan timbal balik antara individu dengan individu, individu dengan kelompok, atau kelompok dengan kelompok. Interaksi dalam pembelajaran adalah hubungan timbal balik antara siswa dengan siswa maupun antara siswa dengan guru dalam suatu kegiatan pembelajaran. Dalam proses interaksi dibutuhkan beberapa komponen antara lain tujuan, prosedur, materi, aktivitas siswa, guru sebagai motivator, kedisiplinan, waktu, dan unsur penilaian.

Latar belakang budaya mempunyai kontribusi terhadap terjadinya interaksi dalam pembelajaran. Dalam budaya Indonesia, khususnya budaya Flores, siswa yang pandai biasanya mempunyai karakteristik: pendiam, penurut, jarang protes pada guru, aktivitasnya sangat terbatas dan jarang berinteraksi pada saat pembelajaran. Akibatnya, siswa tidak terbiasa mengemukakan pendapatnya di kelas, kurang aktif dalam pembelajaran, sehingga kurang dapat mengoptimalkan potensinya. Pembelajaran yang terjadipun cenderung satu arah. Padahal tuntutan kurikulum 2013 mewajibkan siswa untuk aktif dalam pembelajaran. Marpaung (2003) mengatakan bahwa sebagian besar siswa pada sejumlah sekolah takut pada matematika. Lebih lanjut ia berpendapat bahwa guru matematika kurang percaya diri dan jarang tersenyum, sehingga situasi kelas tidak memungkinkan terjadinya interaksi, dan siswa tidak mempunyai kesempatan untuk mengkomunikasikan penyelesaian masalah yang mereka dapatkan.

Salah satu model yang menjanjikan dalam pembelajaran matematika adalah Model interaksi Leikin. Dalam filosofi model interaksi Leikin mewajibkan belajar matematika harus dikaitkan dengan realitas, dan matematika seharusnya dipandang sebagai suatu kegiatan manusia (Freudenthal, 2002). Dengan pengertian lain, matematika harus "dekat" dengan siswa dan relevan dengan situasi kehidupan sehari-hari. Meskipun demikian, matematika tidak hanya berarti berhubungan dengan dunia nyata, tetapi juga berarti situasi masalah (problem situations) yang nyata atau yang dapat dibayangkan oleh siswa. 
Permasalahan utama dalam penelitian ini adalah kurangnya aktivitas interaksi siswa dalam pembelajaran matematika di kelas. Interaksi yang dimaksud adalah kegiatan umpan balik dari siswa kepada guru, siswa dengan siswa dalam berdiskusi dan siswa dengan sumber belajar dalam pemahaman materi pelajaran. Interaksi dapat berupa pertanyaan dari siswa kepada guru, menjawab pertanyaan guru, berdialog antara siswa dalam diskusi kelompok atau menyampaikan ide, gagasan dan tanggapan terhadap materi yang dipelajari. Semua kegiatan ini terjadi dalam proses pembelajaran di kelas.

Pembelajaran merupakan upaya penataan lingkungan yang memberi nuansa agar program belajar tumbuh dan berkembang secara optimal (Johnson, 2017). Sedangkan belajar merupakan suatu proses aktif, yang menuntut siswa harus berpartisipasi dalam kegiatan tersebut. Dengan demikian proses belajar bersifat internal dan unik dalam diri individu siswa, sedangkan pembelajaran bersifat eksternal yang sengaja direncanakan. Beberapa hasil penelitian menekankan pentingnya interaksi siswa dalam proses pembelajaran matematika (Johnson, 2017; Susanto, 2016; Leikin \& Zaslavsky, 1997).

Secara eksplisit bentuk-bentuk interaksi yang berupa negosiasi, penjelasan, pembenaran, persetujuan, pertanyaan atau refleksi digunakan untuk mencapai bentuk matematika formal dari bentuk-bentuk informal yang sudah ditemukan siswa. Dalam pembelajaran ini, siswa terlibat dalam menjelaskan, menjustifikasi, menyetujui atau tidak menyetujui, bertanya tentang alternatif-alternatif dan melakukan refleksi. Jadi harapan hasil penelitian ini adalah siswa terbiasa aktif melakukan interaksi dalam proses pembelajaran,

Menurut teori konstruktivis, pengetahuan merupakan hasil konstruksi manusia melalui interaksi dengan objek, fenomena, pengalaman, dan lingkungan (Lester, 2017). Pendapat tersebut mengisyaratkan bahwa seseorang membangun pengetahuannya yang baru berdasarkan pengetahuan yang telah ada dan dimiliki sebelumnya, yang dapat diperoleh melalui pengalaman, baik secara fisik maupun non fisik. Pandangan kognitifnya melihat belajar bukan semata merupakan unit perilaku yang pasif yang terlahir akibat stimulus, tetapi merupakan proses aktif dimana individu menggunakan prinsip dan hukum dalam penerapannya. Dengan kata lain, proses belajar merupakan suatu proses dimana individu sendiri sengaja membuat hal itu terjadi melalui proses menerima dan menggunakan informasi.

Perkembangan kognitif anak bergantung pada seberapa jauh anak tersebut memanipulasi dan berinteraksi dengan lingkungannya. Adaptasi terhadap lingkungan dilakukan melalui proses asimilasi dan akomodasi. Yang dimaksud asimilasi adalah proses mengabsorbsi pengalaman-pengalaman baru ke dalam scheme yang sudah dimiliki (Hudojo, 2001). Sedangkan akomodasi adalah proses mengabsorbsi pengalaman-pengalaman baru dengan jalan mengadakan modifikasi skema yang sudah ada atau bahkan membentuk pengalaman atau membentuk skema yang benar-benar baru. Proses akomodasi akan menghasilkan penstrukturan kembali mental sebagai akibat adanya informasi dan 
pengetahuan baru. Dengan demikian dapat dikatakan bahwa belajar merupakan proses mengasimilasikan dan mengakomodasikan pengalaman atau pengetahuan yang dipelajari dengan pengetahuan yang telah dimiliki sehingga pengetahuan berkembang.

Perkembangan pengetahuan siswa memerlukan sesuatu agar siswa tersebut dapat menggunakan ide, keterampilan, atau yang lainnya melalui aktivitas yang relevan. Aktivitas tersebut meliputi kombinasi antara pengalaman nyata dengan ide-ide abstrak yang bisa dipresentasikan dalam pembelajaran. Pengetahuan tentang cara berpikir siswa menjadi dasar dalam pembuatan aktifitas yang sesuai, yang mempunyai potensi untuk mendorong belajar yang lebih jauh. Siswa memerlukan orang lain untuk mengubah ide yang bertentangan tersebut agar sesuai dengan ide/konsep yang benar tidak dapat dilakukan sendiri oleh siswa. Siswa memerlukan guru dan teman sebaya yang lebih mampu untuk membimbingnya. Jika siswa tidak mudah mengubah konsep awalnya yang tidak sesuai dengan konsep yang benar, maka perlu diberikan konflik kognitif (cognitive conflict). Disinilah perlunya interaksi antara siswa dengan siswa, maupun antara siswa dengan guru bisa terjadi. Diperlukan banyak perubahan dari pihak guru, maupun siswa, khususnya tentang kebiasaan mengajar dan belajar matematika seperti yang selama ini terjadi.

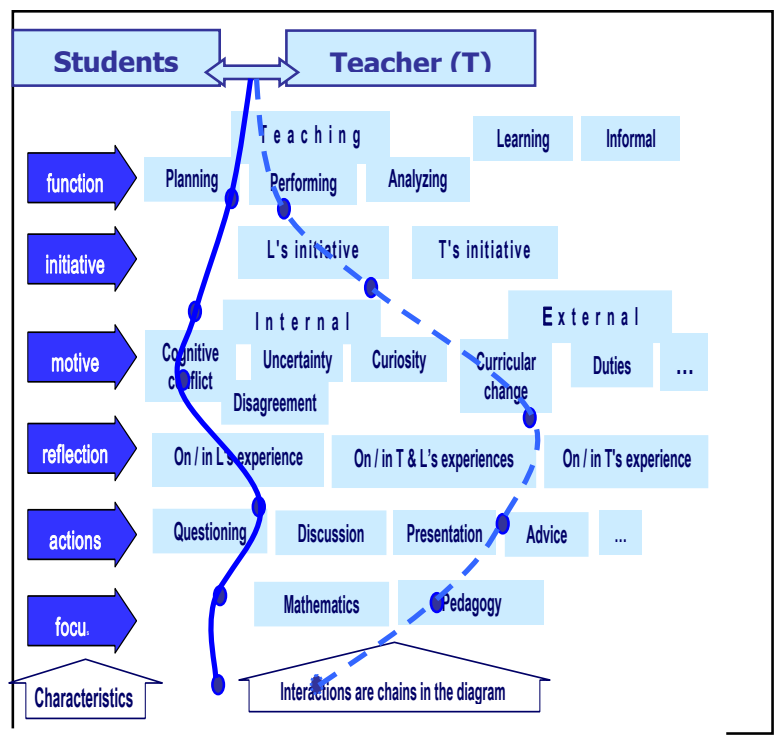

\section{Gambar 1: Model interkasi Leikin}

Gambar 1 merupakan model interaksi Leikin. Leikin (2015) menciptakan suatu model yang memungkinkan analisis rinci tentang interaksi guru dalam suatu sistem enam ciri sebagai berikut 1) tujuan guru berinteraksi dengan siswa, 2) inisiasi (diawali) oleh guru maupun siswa, 3) motif, yang mungkin eksternal jika mereka diatur oleh sistem pendidikan, maupun internal termasuk konflik kognitif, ketidakpastian, ketidaksetujuan, atau rasa ingin tahu, 4) refleksi tentang pengalaman sebelumnya yang dimiliki guru atau siswa, 5) tindakan yang mendukung proses interaktif, misalnya saran, pertanyaan, dan mendiskusikan, 6) fokus interaksi, yang mungkin berupa materi matematika atau pedagogi. Masing-masing tema tersebut dapat dibagi ke dalam kategori luas sehingga setiap 
interaksi dapat dilihat sebagai vector dibangun dari enam "koordinat".

Interaksi yang berlangsung di sekitar kehidupan manusia, menurut Djamarah (2005), dapat diubah menjadi interaksi yang bernilai edukatif, yakni interaksi yang dengan sadar meletakkan tujuan untuk mengubah tingkah laku dan perbuatan seseorang.

\section{METODE}

Penelitian ini dimaksudkan untuk mengeksplorasikan aktivitas siswa melalui model interaksi Leikin. Meskipun demikian, penelitian ini juga termasuk penelitian kualitatif, karena bermaksud untuk mendalami fenomena yang dialami oleh subjek penelitian secara holistik, misalnya tentang perilaku, persepsi, motivasi, dan tindakan subjek penelitian. Selanjutnya, hasil pendalaman tersebut dideskripsikan dalam bentuk kata-kata atau kalimat, pada suatu konteks khusus yang alamiah dan dengan memanfaatkan berbagai metode ilmiah. Dalam penelitian ini fenomena yang akan diungkap adalah proses interaksi yang terjadi dalam pembelajaran matematika yang menggunakan desain interaksi yang dikembangkan oleh peneliti.

Penelitian ini dilaksanakan pada bulan Maret - Mei tahun 2020, dengan tempat penelitian di Sekolah Menengah Pertama Negeri (SMPN) 2 Ende Selatan. Terpilihnya sekolah ini dengan alasan bahwa terdapat banyak siswa yang berkemampuan tinggi dalam hasil belajar, dan mereka berasal dari daerah pinggiran kota, yang jarang berinteraksi dalam pembelajaran di kelas.

Penelitian ini diprioritaskan pada siswa yang berkemampuan tinggi, namun jarang melakukan interaksi dalam pembelajaran, walaupun mereka bisa menjawab pertanyaan guru, namun tidak bisa menyampaikan secara langsung pada saat pembelajaran. Informasi ini diperoleh peneliti jauh sebelum peneliti mengadakan penelitian yaitu berdasarkan perbincangan peneliti dengan guru mata pelajaran matematika pada saat peneliti memberikan pelatihan PTK kepada guru-guru pada bulan Desember tahun 2019. Berdasarkan informasi dari guru mata pelajaran matematika, maka subjek penelitian ini dipilih siswa kelas VIIIA SMPN 2 Ende Selatan. Subjek penelitian berjumlah 20 siswa yang berkemampuan tinggi berdasarkan hasil penilaian guru dalam setiap ulangan dan ujian matematika.

Penelitian ini menggunakan instrumen utama adalah lembar pengamatan aktivitas guru siswa dan instrumen bantu adalah pedoman wawancara dan dokumentasi. Data dalam penelitian ini dikumpulkan melalui kegiatan pembelajaran matematika di kelas melalui model interaksi Leikin. Data utama yang diperoleh yaitu data aktivitas siswa melalui pengamatan dan dokumentasi, sedangkan data pendukung adalah aktivitas guru. Data lain adalah wawancara kepada subjek penelitian mengenai tanggapan atau respon mereka terhadap interaksi yang dilakukannya selama pembelajaran berlangsung.

Data yang terkumpul dalam penelitian ini dilanjutkan untuk dianalisis. Kegiatan yang dilakukan dalam menganalisis data tentang aktivitas siswa dalam pembelajaran antara lain 1) menghitung persentase aktivitas siswa yang diamati dalam pembelajaran, 2) mencari rata-rata persentase aktivitas 
siswa yang diamati dalam pembelajaran, 3) menentukan kategori untuk aktivitas siswa dalam kegiatan belajar mengajar (KBM) dengan cara mencocokkan hasil rata-rata total dengan kriteria yang telah ditetapkan seperti pada tabel berikut.

Tabel 1. Kategori Aktivitas Siswa

\begin{tabular}{|c|c|}
\hline Persentase & Kategori \\
\hline $95 \% \leq \mathrm{KBM}$ & SA (Sangat Aktif) \\
\hline $80 \% \leq \mathrm{KBM}<95 \%$ & A (Aktif) \\
\hline $65 \% \leq \mathrm{KBM}<80 \%$ & KA (Kurang Aktif) \\
\hline $\mathrm{KBM}<65 \%$ & TA (Tidak Aktif) \\
\hline
\end{tabular}

Kegiatan yang dilakukan untuk menganalisis data respons siswa adalah sebagai berikut 1) menghitung banyak siswa yang memberi tanggapan sesuai dengan aspek yang ditanyakan, 2) menghitung persentase dari (1), 3) menentukan kategori untuk respons positif siswa dengan cara mencocokkan hasil persentase dengan kriteria yang telah ditetapkan. Kriteria untuk menyatakan bahwa respons siswa (RS) positif dapat dilihat pada tabel berikut.

Tabel 2. Kriteria Respon Siswa Positif

\begin{tabular}{|c|c|}
\hline Persentase & Kriteria \\
\hline $85 \% \leq \mathrm{RS}$ & $\mathrm{SP}$ (Sangat Positif) \\
\hline $70 \% \leq \mathrm{RS}<85 \%$ & P (Positif) \\
\hline $50 \% \leq \mathrm{RS}<70 \%$ & $\mathrm{KP}$ (Kurang Positif) \\
\hline $\mathrm{RS}<50 \%$ & $\mathrm{TP}$ (Tidak Positif) \\
\hline
\end{tabular}

Dalam penelitian ini terdapat dua pelaku wawancara. Dua pelaku tersebut adalah Tim peneliti, masing-masing peneliti melakukan wawancara dengan 3 orang subjek penelitian yaitu siswa. Siswa yang diwawancarai dipilih 6 orang berdasarkan keaktifan berinteraksi dalam pembelajaran.

Teknik untuk memeriksa kredibilitas data penelitian ini dilakukan dengan cara 1) pertemuan antara peneliti dan pengamat, serta antara peneliti dan guru untuk mengatasi ketidakjelasan atau bias, 2) menguji hasil temuan tentatif dan penafsiran dengan hasil dokumentasi, 3) menguji temuan sebagai sumber/asal data diperoleh.

Untuk menguji dependabilitas (reliabilitas) dalam penelitian ini, akan dilakukan dengan melakukan audit terhadap seluruh aktivitas peneliti dalam melakukan penelitian, yang meliputi cara peneliti menentukan masalah, menentukan sumber data, mengumpulkan data, melakukan analisis data, dan menarik kesimpulan.

\section{HASIL DAN PEMBAHASAN}

Analisis hasil penelitian menggunakan model interaksi Leikin dalam pembelajaran matematika di kelas. Model interaksi Leikin digunakan dalam pembelajaran matematika di kelas dengan materi teorema pythagoras pada siswa kelas VIIIA SMPN 2 Ende Selatan yang berjumlah 20 orang. Hasil yang diukur adalah aktivitas siswa dan respon siswa dengan bantuan model interaksi Leikin. Hasil yang diperoleh dalam penelitian ini 
adalah hasil pengamatan oleh 2 orang penilai yaitu seorang peneliti dan seorang guru yaitu guru wakil kepala sekolah bagian kurikulum. Berikut terdapat 2 tabel analisis hasil pengamatan selama pembelajaran matematika dengan bantuan model interaksi Leikin.

Tabel 3. Aktivitas Pembelajaran dengan Bantuan Model Interaksi Leikin

\begin{tabular}{|c|c|c|c|c|}
\hline No. & $\begin{array}{c}\text { Langkah-langkah } \\
\text { Model } \\
\text { Pembelajaran Leikin } \\
\end{array}$ & Aktivitas Guru & Aktivitas Siswa & $\begin{array}{c}\text { Capaian Interaksi } \\
\text { Aktivitas }\end{array}$ \\
\hline 1 & $\begin{array}{l}\text { Tujuan guru berinteraksi } \\
\text { dengan siswa }\end{array}$ & $\begin{array}{l}\text { Menyajikan materi } \\
\text { teorema phytagoras }\end{array}$ & $\begin{array}{l}\text { Memperhatikan dan } \\
\text { mencatat }\end{array}$ & $\begin{array}{l}\text { Guru } 100 \%, \text { Semua } \\
\text { Siswa } 0 \%\end{array}$ \\
\hline 2 & $\begin{array}{l}\text { Inisiasi (diawali) oleh } \\
\text { guru maupun siswa }\end{array}$ & $\begin{array}{l}\text { Meminta siswa } \\
\text { menyelesaikan } \\
\text { LKS } \\
\end{array}$ & $\begin{array}{l}\text { Bertanya hal yang belum } \\
\text { Dipahami dan } \\
\text { bediskusi }\end{array}$ & $\begin{array}{l}\text { Guru 20\%, Semua } \\
\text { Siswa } 80 \%\end{array}$ \\
\hline 3 & $\begin{array}{l}\text { Konflik internal dan } \\
\text { eksternal }\end{array}$ & $\begin{array}{l}\text { Bertanya hal yang } \\
\text { belum dihahami }\end{array}$ & $\begin{array}{l}\text { Sebagian kecil siswa } \\
\text { bertanya }\end{array}$ & $\begin{array}{l}\text { Guru } 30 \%, 4 \text { siswa } \\
50 \%, 16 \text { siswa } 20 \%\end{array}$ \\
\hline 4 & Refleksi & $\begin{array}{l}\text { Guru meminta } \\
\text { kelompok siswa } \\
\text { presentasi }\end{array}$ & $\begin{array}{l}\text { Kelompok siswa presentasi } \\
\text { hasil diskusi }\end{array}$ & $\begin{array}{l}\text { Guru 10\%, Siswa } \\
80 \%\end{array}$ \\
\hline 5 & $\begin{array}{l}\text { Tindakan yang } \\
\text { mendukung proses } \\
\text { interaktif, }\end{array}$ & $\begin{array}{l}\text { Menyimpulkan isi } \\
\text { materi }\end{array}$ & $\begin{array}{l}\text { Bersama guru } \\
\text { menyimpulkan materi }\end{array}$ & $\begin{array}{l}\text { Guru 50\%, Siswa } \\
50 \%\end{array}$ \\
\hline 6 & $\begin{array}{l}\text { Fokus interaksi, yang } \\
\text { mungkin }\end{array}$ & Menutup pelajaran & Bertanya soal tugas & $\begin{array}{l}\text { Guru 50\%, Siswa } \\
50 \%\end{array}$ \\
\hline
\end{tabular}

Sumber: Data primer penelitian

Tabel 4. Analisis Aktivitas Pembelajaran dengan Bantuan Model Interaksi Leikin

\begin{tabular}{|c|c|c|}
\hline Capaian & $\begin{array}{c}\text { Pengamatan } \\
\text { Guru }\end{array}$ & $\begin{array}{c}\text { Pengamatan } \\
\text { Siswa }\end{array}$ \\
\hline 1 & $100 \%$ & $0 \%$ \\
\hline 2 & $20 \%$ & $80 \%$ \\
\hline 3 & $30 \%$ & $70 \%$ \\
\hline 4 & $10 \%$ & $80 \%$ \\
\hline 5 & $50 \%$, & $50 \%$ \\
\hline 6 & $50 \%$ & $50 \%$ \\
\hline
\end{tabular}

Sumber: Data primer penelitian

Pengamatan terhadap aktivitas guru dilakukan oleh peneliti selama melaksanakan proses pembelajaran, dengan mengunakan lembar observasi pelaksanan pembelajaran. Hasil pengamatan dapat terlihat pada tabel berikut.

Tabel 5. Aktivitas Guru

\begin{tabular}{|c|l|c|c|}
\hline No. & $\begin{array}{c}\text { Pelaksanaan } \\
\text { pembelajaran }\end{array}$ & Aktivitas guru & Kriteria \\
\hline 1 & Tujuan interaksi & 4,75 & Sangat Tinggi \\
\hline 2 & Inisiasi & 2,0 & Rendah \\
\hline 3 & Konflik & 3,0 & Cukup \\
\hline 4 & Refleksi & 4,25 & Tnggi \\
\hline 5 & Tindakan pendukung & 4,25 & Tinggi \\
\hline 6 & Fokus & 3,25 & Cukup \\
\hline \multicolumn{2}{|c|}{ Rata-rata } & $\mathbf{3 , 5 8}$ & Tinggi \\
\hline
\end{tabular}

Sumber: Hasil analisis 
Dari tabel diketahui bahwa rata-rata aktivitas guru dalam pembelajaran matematika dengan bantuan model Interaksi Leikin diperoleh nilai 3,58 terletak pada kriteria tinggi.

Tabel 6. Aktivitas Siswa

\begin{tabular}{|c|l|c|c|}
\hline No. & $\begin{array}{l}\text { Pelaksanaan } \\
\text { pembelajaran }\end{array}$ & Aktivitas Siswa & Kriteria \\
\hline 1 & Tujuan inteaksi & 4,85 & Sangat Tinggi \\
\hline 2 & Inisiasi & 2,75 & Rendah \\
\hline 3 & Konflik & 3,0 & Cukup \\
\hline 4 & Refleksi & 4,0 & Tnggi \\
\hline 5 & Tindakan pendukung & 4,25 & Tinggi \\
\hline 6 & Fokus & 3,00 & Cukup \\
\hline & Rata-rata & $\mathbf{3 , 6 4}$ & Tinggi \\
\hline
\end{tabular}

Sumber: Hasil analisis

Dari tabel diketahui bahwa rata-rata aktivitas siswa dalam pembelajaran matematika dengan bantuan model Interaksi Leikin diperoleh nilai 3,64 terletak pada kriteria tinggi.

Wawancara diadakan setelah melaksanakan proses pembelajaran.Wawancara dilakukan oleh tim peneliti terhadap 6 orang siswa yang mengikuti kegiatan pembelajaran. Enam siswa tersebut adalah siswa yang memiliki aktivitas sesuai kriteria tinggi, sedang dan rendah, masing-masing berjumlah 2 orang. Wawancara digunakan untuk mengetahui respon siswa terhadap model interaksi Leikin yang dilakukan selama proses pembelajaran. Hasil wawancara terhadap 6 siswa tersebut menggambarkan respon mereka terhadap pembelajaran dengan bantuan model interaksi Leikin yang dilakukan oleh peneliti, dengan menggunakan pedoman wawancara yang ditunjukan pada tabel berikut.

Tabel 7. Respon Siswa

\begin{tabular}{|c|c|c|c|}
\hline No. & Pelaksanaan pembelajaran & Respon Siswa & Kriteria \\
\hline 1 & Tujuan inteaksi & $60 \%$ & Kurang positif \\
\hline 2 & Inisiasi & $80 \%$ & Sangat positif \\
\hline 3 & Konflik & $75 \%$ & Positif \\
\hline 4 & Refleksi & $85 \%$ & Sangat positif \\
\hline 5 & Tindakan pendukung & $70 \%$ & Kurang positif \\
\hline 6 & Fokus & $75 \%$ & Positif \\
\hline \multicolumn{2}{|r|}{ Rata-rata } & 74,16 & Tinggi \\
\hline
\end{tabular}

Sumber: Hasil Analisis

Dari tabel diketahui bahwa rata-rata respons siswa terhadap pembelajaran dengan bantuan model Interaksi Leikin diperoleh nilai 74,16, terletak pada kriteria tinggi. 
Selanjutnya analisis data hasil wawancara dengan 2 guru yaitu guru matematika yang menjalankan pembelajaran dengan bantuan model interaksi Leikin dan guru pengamat aktivitas siswa. Hasil yang diperoleh dari 2 guru tersebut disimpulkan bahwa guru menjalankan proses pembelajaran sesuai langkah-langkah pada model interaksi Leikin. Dan hasil wawancara dengan 6 siswa disimpulkan bahwa dengan bantuan model interaksi Leikin dalam pembelajaran matematika, siswa termotivasi untuk lebih aktif dalam bertanya kepada guru dan bertanya kepada teman yang mempresentasikan hasil kerja kelompok, siswa aktif menjawab pertanyaan guru, jika guru bertanya dan siswa aktif berdiskusi dalam kelompok belajar untuk menyelesaikan soal-soal yang diberikan.

Berdasarkan hasil penelitian yang diperoleh, menunjukkan bahwa 1) pelaksanaan pembelajaran matematika dengan bantuan model interaksi Leikin, dapat membantu guru dengan adanya interaksi dari siswa sehingga pembelajaran berjalan normal. Hal ini ditunjukkan oleh hasil analisis berada pada rata-rata 3,58 terletak pada kriteria tinggi, 2) pembelajaran matematika dengan bantuan model interaksi Leikin, dapat membangkitkan aktivitas siswa yang ditunjukkan oleh hasil analisis berada pada rata-rata 3,64, terletak pada kriteria tinggi, 3) hasil analisis respon siswa yang mengikuti pelajaran yaitu mencapai nilai rata-rata 74,16 terletak pada kriteria tinggi.

\section{KESIMPULAN}

Pelaksanakan pembelajaran matematika dengan bantuan model interaksi Leikin, dapat membangkitkan aktifitas siswa, dari yang selama ini hanya pasif dan menjawab soal dengan tenang, sudah bias bersuara untuk menjawab dan bertanya kepada guru dan kepada teman pada saat temannya mempresentasikan hasil kerja kelompoknya. Hasil penelitian sudah menunjukkan tingkat aktivitas siswa berada pada tingkat tinggi. Hal lain dari penerapan model interaksi Leikin dapat ditunjukkan dengan respon siswa yang mengikuti pelajaran dari hasil wawancara dengan mereka sangat membantu siswa untuk aktif yaitu mencapai nilai rata-rata 74,16 terletak pada kriteria tinggi.

\section{DAFTAR PUSTAKA}

Freudenthal, H. (2002). Revisiting Mathematics Education. New York: Kluwer Academic Publishers.

Holil, A. (2009). Ineraksi Sebagai Proses Belajar Mengajar. http.// anwarholil.Com. Diakses pada 15 April 2020

Hudojo, Herman. (2001). Psikologi Kognitif untuk Pengembangan Kurikulum dan Pembelajaran Matematika. Departemen Pendidikan dan Kebudayaan, Jakarta.

Johnson, Elaine B.(2017). Contextual teaching and Learning Menjadikan Kegiatan Belajar Mengajar Mengasyikan dan Bermakna.Terjemahan Ibnu setiawan. Bandung: mizan learning Center.

Leikin Roza.(2015). Interaksi dalam Pembelajaran Matematika Guru Fokus Pada Simetri. https://id.scribd.com.document. Diakses pada 15 April 2020. 
Leikin, R., Zaslavsky, O. (1997). Facilitating Student Interaction in Mathematics in Cooperative Learning Setting. Journal for Research in Mathematics Education. Vol.28 No.3, 331-354, NCTM.

Lester, Frank K.(2017). Research on Mathematical Problem Solving. Shumway, the national Council of Teachers of Mathematical, Inc.

Marpaung, Y. (2003). Pembelajaran Paradigma Pembelajaran Matematika dari paradigma Mengajar ke Paradigma Belajar". Makalah. Disampaikan dalam Seminar Seminar Nasional Pendidikan Matematika Realistik di USD, 27-28 Maret 2003.

Sukmadinata. (2009). Landasan Psikologi dan Proses Pendidikan. Bandung: PT Remaja Rosdakarya.

Susanto, A. (2016). Teori Belajar dan Pembelajaran. Jakarta: Prenada Media Group. 